\title{
Llano Alonso. Fernando. H., El gobierno de la razón: la filosofía jurídico- política de Marco Tulio Cicerón, Pamplona, Cizur Menor Thomson Reuters Aranzadi, 2017, 201 pp.
}

Adolfo Jorge Sánchez Hidalgo

Universidat de Códoba

Fecha de recepción 01/03/2018 I De publicación: 27/06/2018

El profesor Llano Alonso ha publicado recientemente la obra El gobierno de la razón: la filosofía jurídico-política de Marco Tulio Cicerón, la cual es el resultado de varios años de investigación a caballo entre Sevilla y Oxford. Este volumen presenta numerosas muestras de las virtudes académicas del autor, al igual que un intachable objetivismo en la interpretación del pensamiento filosófico del genial jurista romano. Además, compagina este rigor científico con una redacción fluida, párrafos sintéticos y concisos, así como una admirable estructuración de las ideas. Sólo por estas razones su lectura debe ser una obligación para todos aquellos amantes de los clásicos en busca de inspiración y nuevas enseñanzas.

Se aprecia en cada una de sus páginas cómo el autor ha deslizado su espíritu de historiador (señal distintiva de la escuela sevillana), escudriñando los diferentes puntos de interés de la obra de CICERÓN y conectándolos biográficamente con el personaje, para presentarnos una imagen lo más certera posible del legendario cónsul romano-. CICERÓN es un autor sobre el que hay escrita una ingente cantidad de bibliografía $y$, no obstante, la monografía del profesor sevillano está llamada a ocupar un lugar de honor. No sólo porque se hace eco de algunos geniales estudios del pasado; sino, sobre todo, porque sabe continuar el camino trazado, avanzando sus pasos y orillando una novedosa proyección del personaje en el devenir histórico. El gerundio es la forma verbal que tiene el lenguaje para ofrecernos el presente haciéndose, en movimiento, y quizá sea ésta una de las grandes virtudes de este libro: hacer presente a CiCERÓn. Porque, efectivamente, la investigación del profesor LLANO ALONSO no se agota en el estudio de los antecedentes y obra del rétor romano. Más aún, con elogiable ambición, intenta explicar el recorrido histórico de las ideas del Arpinate y cómo subsisten en el presente con 
revivida gloria. En este sentido, el Epílogo es una verdadera apología del pensamiento ciceroriano para el agitado presente político.

En el decurso de la obra hay un claro leitmotiv entre sus páginas, en sus cuatro capítulos, y éste es la presentación de la filosofía del genial orador como la evocación de la excelencia ética. Un genuino canto a la virtud y al engrandecimiento del espíritu humano que, progresivamente, ha forjado la cultura humanista de todas las épocas. La identificación de CICERÓN con la excelencia y la exaltación de la virtus ciudadana, no es una idea original de esta obra, incluso, poco después de su muerte, QUINTILIANO le hacía merecedor de tal consideración ${ }^{1}$. La novedad de este libro consiste en resaltar esta invocación de la virtud ciudadana como fundamento de la ética política a lo largo de la historia, de modo que la encontramos en las ideas de los principales pensadores de la civilización occidental $^{2}$. De ello, da buena cuenta esta obra.

Debe elogiarse la estructuración temática de esta monografía, porque se aleja de alambicadas reflexiones y complejas conexiones de sentido, cuya única meta parezca ser dificultar la lectura y fatigar la mente. Al contrario, en su

1 QUINTILIANO, Obra completa, IV, Instituciones Oratorias, XII, I, Universidad Pontificia de Salamanca, 2000, p. 294. “16. Nec M. Tulio defuisse video in nulla parte civis optimi voluntatem".

${ }^{2}$ LLANO ALONSO, F. H., El gobierno de la razón: filosofía jurídico-política de Marco Tulio Cicerón Pamplona, Cizur menorThomson Reuters-Aranzadi, 2017, pp. 79-122. índice se observa el buen hacer del profesor universitario, que establece los linderos de su investigación y cultiva ordenadamente la sabiduría con cuidadas reflexiones y fértiles argumentos de autoridad - muchos de ellos extraídos de las longevas bibliotecas de Oxford -. La consecuencia de este mimado método de investigación es que para el lector será sumamente sencillo recoger los frutos o enseñanzas que se desprenden maduras de los capítulos y epígrafes del libro. El autor se aparta del resto de la literatura sobre CiCERÓN por su forma: no sigue la simple exposición de hechos ateniéndose rigurosamente a la cronología, ésta es respetada; pero el relato científico se libera, se llena de detalles, intercala novedades, interpreta opiniones, trata de actitudes, se adapta al plan expositivo, se entrega a la información y a la satisfacción de la curiosidad del lector.

No deseo adelantar en exceso el contenido de un libro de lectura muy recomendable. Más bien, mi intención es despertar este interés entre la comunidad universitaria, para ello voy a presentar las tres partes de la obra y, como si de una pequeña degustación se tratase, las principales virtudes de cada una de ellas y las observaciones que, a mi juicio, despiertan. Así, la primera parte está dedicada a la filosofía del derecho de CICERÓn; la segunda parte se ocupa del pensamiento republicano de CICERÓN y su 
legado doctrinal; y la tercera se centra en la ética humanista y universal del Arpinate.

\section{El pensamiento iusfilosófico de Marco Tulio} Cicerón.

A pesar de que en la doctrina germana y anglosajona se considera a CICERÓN como un abogado, lo cierto es que él mismo nunca llego a considerarse jurista. No obstante, su ocupación como rethor, así como las magistraturas que llegó a desempeñar, le proporcionaron una vastísima cultura jurídica. El profesor LlANO ALONSO destaca, dentro de esta formación jurídica, a sus maestros Quinto y PUBlio Escá́vola y a sus amigos juristas Servio SulPicio RUfo y Gayo Trebacio. Dada la importancia que el Derecho tuvo en la formación de Cicerón, no debe extrañarnos que desde los inicios, los problemas iusfilosóficos ocuparán un lugar central en el conjunto de su filosofia ${ }^{3}$.

La obra del profesor sevillano presta especial atención a la idea de Derecho natural en CICERÓN, que se contiene principalmente en los tratados De Republica y De Legibus. En ellos, el Arpinate hace referencia a la suprema razón inscrita en la naturaleza humana, a la cual se le ha de llamar propiamente ley, pues, está llamada a presidir la conducta de los hombres y sus leyes

${ }^{3}$ Ibidem, p. 20. civiles. El profesor LLANO concluye que CICERÓN supera el naturalismo fisicalista de la tradición griega y centra su concepción del Derecho natural en la naturaleza humana, en su potencia racional, lo que lo aproxima a las corrientes intelectualistas por venir ${ }^{4}$.

Precisamente, como la ley natural encuentra su fundamento en la naturaleza racional del hombre es común a todo el género humano y su fuerza se despliega por igual en todas las ciudades y es la causa común de todo Derecho y ética. Una nueva prueba del cosmopolitismo universalista de Cicerón, que nuestro autor no pasará por alto 5 .

La idea de justicia, según Llano Alonso, significa para CICERÓN - al igual que para ARISTÓTELES - la virtud central de todas las demás virtudes y se encuentra determinada por la idea de alteridad, es decir, la fuerza que (el otro) los demás ejercen sobre la acción del individuo. La justicia es, en consecuencia, una virtud intersubjetiva que orienta la acción conforme al general principio "a cada cual lo suyo"; pero, también, la sabiduría o prudencia necesaria para dominar nuestras pasiones y presidir nuestra acción.

\footnotetext{
${ }^{4}$ Ibidem, p. 24.

${ }^{5}$ Ibidem, p. 27.
} 
Al respecto del pensamiento iusfilosófico del "perfecto orador"," debe destacarse, en el agudo análisis del profesor sevillano, la aclaración del concepto de ley natural como ley común al género humano de carácter universalista fundada en la naturaleza racional del hombre ${ }^{7}$. No en vano, para CICERÓN la recta razón se relaciona directamente con la divinidad y es el cimiento común de toda la república y sus leyes. En consecuencia, la potencia racional del hombre se convierte en el origen de todo mandato ético, pero, también, en cuanto se proyecta hacia los demás, posee una vocación de ordenación de las relaciones humanas de todo género - comenzando por la familia y acabando en la humanitas -. La ética y el derecho hallan en la naturaleza racional del hombre su fundamento último y, por ello, el derecho natural (dictámenes de la recta razón) tiene un carácter universal e inderogable ${ }^{8}$. Cabría preguntarse en qué clasificación teórica del derecho natural encaja la visión de CICERÓN y se afirmará, con fundamento, que se trata de una visión intelectualista del derecho natural. Ahora bien, a mi juicio, se trata de una visión iusnaturalista que oscila entre el intelectualismo tomista y el racionalismo kantiano. Distante de la idea de derecho natural de TOMÁs por faltar en CICERÓN la idea cristiana de Dios y la revelación;

\footnotetext{
${ }^{6}$ QUINTILIANO, op. cit., Instituciones Oratorias, XII, I, p. 297.

${ }^{7}$ LLANO ALONSO, F. H., El gobierno de la razón, op. cit., p. 27.

${ }^{8}$ LLANO ALONSO, F. H., "Cicero and Natural Law", Archivs fur

Rechts-und Soziaphilosophie, Vol. 98, n. 2, 2012, p. 161.
}

e, igualmente, alejada de la noción racionalista de KANT, porque la idea de derecho natural ciceroniano difícilmente puede interpretarse como una preceptiva de reglas deducidas de la razón ${ }^{9}$. El derecho natural del Arpinate y su noción de racionalidad, no deben entenderse independientemente del acontecer humano, más bien, hay que hallarlos en el suceder de los tiempos. La fuerza ordenadora de la razón es la fuerza misma que mana de la ejemplaridad, de modo que el esfuerzo por conocer el contenido de la ley natural es el esfuerzo por perseguir, hallar y emular lo que de excelente hay en las acciones humanas.

Así mismo, es necesario engrandecer el análisis ciceroniano acerca de la justa causa y el ritualismo formal de la declaración de guerra como causas necesarias para su legitimidad, lo que el autor del libro no duda en conectar con las teorías de autores renacentistas como VITORIA ${ }^{10}$. Ciertamente, CICERÓN y VITORIA pueden encuadrarse en la posición del pacifismo moderado que observa la guerra como un mal necesario, última ratio, para la preservación de la paz. En CiCERón la justa causa es una premisa ética delimitada ampliamente por la justicia y la buena fe (p. 36); en cambio, para VITORIA la cuestión de la justa causa queda mejor perfilada,

\footnotetext{
${ }^{9}$ CARPINTERO BENÍTEZ, F., La cabeza de Jano, Universidad de Cádiz, 1989, pp. 32-35.

${ }^{10}$ LLANO ALONSO, F. H., El gobierno de la razón, op. cit., p. 36.
} 
pues, establece una tópica de títulos que se relacionan directamente con varios bienes jurídico-morales, como: el derecho a la comunicación, la libertad de conciencia, la igual dignidad humana, la propiedad, etc ${ }^{11}$. En definitiva, para VITORIA la intervención bélica se justifica como último recurso y en la medida en que se oriente a proteger y garantizar los bienes derivados de la dignidad humana (Imago Dei $)^{12}$.

En otro orden de cosas, es especialmente reseñable cómo FERNANDO LLANO logra compatibilizar y explicar los diversos sentidos del término aequitas en la obra del Arpinate, algo que, sin lugar a dudas, será de gran ayuda a los investigadores de nuestra disciplina ${ }^{13}$. Acertadamente, se distingue en CICERÓN la equidad como criterio (virtud) de ponderación para la justicia retributiva y distributiva, de la equidad como criterio corrector de la generalidad de la ley ${ }^{14}$. Actualmente, se mantiene este doble sentido en nuestro ordenamiento jurídico. Así, el Código Civil utiliza la palabra "equidad" para la ponderación de las prestaciones, es decir, como criterio de proporcionalidad $\mathrm{y}$, de manera muy excepcional, podemos encontrar en la

\footnotetext{
11 APARISI MIRALLES, A., Derecho a la paz y derecho a la guerra en Francisco de Vitoria, Granada, Comares, 2007, pp. 6173.

12 FERNÁNDEZ RUIZ-GÁlVEZ, E., "El totus Orbis y el ius gentium en Francisco de Vitoria: el equilibrio entre tradición e innovación”, Cuadernos electrónicos de Filosofía del Derecho, 35, 2017 , p. 40.

${ }^{13}$ LLANO ALONSO, F. H., El gobierno de la razón, op. cit., p. 40.

${ }^{14}$ Ibidem, p. 41.
}

jurisprudencia el uso de la equidad como criterio corrector de la ley, fundándolo en el artículo 3.2 del mismo Código. Como muestra de la identificación entre equidad y proporcionalidad podemos citar los artículos 1154 y 1690 del Código Civil. Como prueba de la función correctora de la generalidad de la norma, que desempeña la equidad, debemos remitirnos a sentencias como las siguientes: (STS 9 de mayo 1983, RJ1983/2678; STS 10 octubre 1986, RJ1986/5511; 28 marzo 1990, RJ1990/1734; 30 diciembre 1998, RJ1251/1998; 18 marzo 2002, RJ 240/2002; entre otras).

Particularmente reveladora resulta la explicación que hace FERNANDO LLANO acerca de la posición de CICERÓn sobre la equidad como criterio corrector de la ley. Comienza recordando la línea de continuidad existente entre la Ética a Nicómaco de ARISTÓteles y las Filípicas de CICERÓN, en virtud de la cual, la equidad no es sino la correcta interpretación del derecho adaptada a las circunstancias particulares ${ }^{15}$. De las lecturas de los argumentos en defensa de CECina o a favor de los honores fúnebres de Servio Sulpicio, se extrae una visión de la equidad como criterio orientador del razonamiento jurídico, que debe guiar tanto la comprensión de los hechos sometidos a controversia, como la intelección de la norma aplicable. En virtud de la equidad, CICERÓN

${ }^{15}$ Ibidem, pp. 44-47. 
exhorta a comprender las normas a la luz de los hechos y la fuerza de su individualidad, moderando el tenor literal y generalista de los preceptos legales.

Este primer capítulo concluye con el desarrollo de la idea de ius gentium en el pensamiento de Cicerón, la cual, de acuerdo con el autor, se sitúa en una posición intermedia entre el derecho natural y el ius civile. El derecho de gentes se trata al igual que el ius civile de un derecho positivo, que vincula a todos los pueblos $\mathrm{y}$, en esto difiere del particular ius civile romano. El derecho de gentes comparte con el derecho natural la vocación universal; sin embargo, el ius gentium se contiene en normas positivas, mientras que el derecho natural es el dictado de la recta razón (sustrato de todo derecho) ${ }^{16}$. No debe descuidarse el hecho de que estamos presentes ante una de las más logradas explicaciones jerárquicas del orden jurídico, que influirá decisivamente en los planteamientos medievales acerca del Derecho; por ejemplo, esta visión intermedia del ius gentium, será desarrollada con notable éxito por el internacionalista burgalense FRANCISCO DE VITORIA ${ }^{17}$.

\section{El pensamiento republicano de CICERón y} su legado doctrinal.

El capítulo segundo y tercero lo dedica nuestro autor al estudio del pensamiento republicano en CICERÓN y su influencia en la historia de la civilización occidental, desde el Renacimiento hasta los orígenes de la tradición liberal constitucionalista. Este capítulo es, a mi parecer, uno de los capítulos de historia de las ideas más logrados en la bibliografía contemporánea. Toda vez que el iusfilósofo sevillano consigue mostrar las profundas convicciones políticas del maestro romano, comienza a trazar la proyección histórica de las mismas. Gracias a la cual, el lector podrá comprobar en qué medida algunas ideas son bienes del espíritu y están llamadas a discurrir eternamente en aras de su realización. Este capítulo desprende todo él un aroma oxoniense. Con particular genialidad, LLANO ALONSO recorre la historia del constitucionalismo inglés junto a las enseñanzas del republicanismo romano de CICERÓN $^{18}$; pero, por si fuera poco, no bastándole Inglaterra en este decurso, Fernando LLANO cruza el océano atlántico hacia orillas estadounidenses ${ }^{19}$.

${ }^{18}$ LLANO ALONSO, F. H., El gobierno de la razón, op. cit., pp. 97-116.

${ }^{19}$ Ibidem, pp. 117-120.

${ }^{16}$ Ibidem, pp. 47-49.

${ }^{17}$ FERNÁNDEZ RUIZ-GÁLVEZ, E., op. cit., p. 37 
Nuestro autor observa con precisión la convivencia en los escritos ciceronianos de las tesis aristotélicas-estoicas y epicureístas, acerca del origen de la comunidad civil. En los primeros escritos CICERÓn ve en la indigencia y debilidad humana la causa de la comunidad política; pero en sus escritos de madurez (De Republica, De Legibus y De Officis) mantiene la posición aristotélica, en virtud de la cual es el natural apetito de sociedad la causa de las comunidades humanas y políticas ${ }^{20}$. Claro está, para el Arpinate la república no es, sin más, el resultado del acontecer natural, ésta exige la participación de la razón y voluntad humana, que toma la forma de un derecho común (iuris consensu). Siguiendo el método tradicional escolástico del scire per causas, FERNANDO LLANO nos muestra, a lo largo de estas páginas, la naturaleza de esta República: encuentra $\mathrm{su}$ origen (causa agente) en la sociabilidad humana y su natural desenvolvimiento en grados sucesivos; su objeto es la convivencia humana (causa material); de acuerdo con un derecho común (causa formal); y cuya finalidad (causa final) es la preservación de la amistad, la salud pública o el bien común de los ciudadanos $^{21}$.

A esta visión ontológica de la República, como ciertamente observa el autor, se le debe añadir el conjunto de principios de teoría política

\footnotetext{
${ }^{20}$ Ibidem, p. 60.

${ }^{21}$ Ibidem, pp. 56-63.
}

que CICERÓN extrae de la experiencia romana. Por ello, la originalidad de CICERÓN no se halla tanto en el estudio del "ser" de la República, como en el detalle de cómo ha de preservarse la misma. En este sentido, las tesis filosóficas acerca del origen de la República, dejan paso a una verdadera teoría republicana cuyo último fin es la preservación de la comunidad o el bien común ${ }^{22}$.

En esta teoría política, Llano AlONSO, destaca tres ideas de extraordinaria fuerza a lo largo de la historia del hombre: a) el imperio de la ley; b) la idea de constitución mixta; y c) el poder como "oficio" o responsabilidad ética.

a) El imperio de la ley se traduce en el pensamiento político de CICERÓN como una auténtica necesidad para preservar la libertad de los miembros de la ciudad. La idea de República encuentra su exteriorización en un derecho común a todos los ciudadanos, que vincule por igual a todos sus miembros y en cuyo respeto se funde la verdadera libertas. No existe libertad, cuando la República es gobernada tiránicamente con desprecio hacia las leyes que la constituyen y sometiendo a la ciudadanía a los caprichos del gobernante, sea uno, varios o la multitud. El respeto a las leyes es la condición necesaria para la convivencia social, gracias a ellas el hombre puede desarrollar su libertad política de forma

${ }^{22}$ Ibidem, p. 56. 
plena: "Legum omnes servi sumus, ut liberi esse possimus ${ }^{\prime 23}$.

b) CICERÓN considera la finalidad propia de la República, en esto coincide con toda la tradición aristotélica, el bien de la comunidad. Lo que es bueno para la comunidad no puede ser diferente de aquello que garantiza la paz, la amistad y la concordia. CICERÓN comparte con la tradición anterior la idea de tres formas puras de gobierno y tres formas tiránicas o impuras del mismo. De acuerdo con este legado doctrinal tanto la monarquía, como la aristocracia y la democracia pueden lograr el bien de la comunidad, no obstante, sus desviaciones (tiranía, oligarquía y demagogia) lo hacen imposible. FERNANDO LLANO resalta en CICERÓN una primera formulación de la anacyclosis, en virtud de la cual, toda forma pura de gobierno tiende a su corrupción con el paso del tiempo. Esta natural tendencia a la corrupción, que observa Cicerón, en las formas clásicas de gobierno le conduce a idear una constitución mixta, que garantice el bien común y preserve la República de la degeneración ${ }^{24}$. En esta constitución se combinan equilibradamente la monarquía, la aristocracia y la democracia. En el pensamiento de CICERÓN es la forma óptima de gobierno, porque se funda en el equilibrio de poder y hace posible la concordia

${ }^{23}$ Ibidem, p. 68.

${ }^{24}$ Ibidem, p. 62. entre las diferentes capas sociales ${ }^{25}$. El modelo en el que se inspira el Arpinate es, a todas luces, el modelo de la república romana que combina el carácter regio de las magistraturas, con las virtudes aristocráticas del senado y la libertad ciudadana protegida por las leyes, que vinculan por igual a todos (isonomia).

c) El ejercicio del poder entendido como un "oficio", esto es, de vocación ética. Para CICERÓN, la política no es un quehacer vulgar, sino una verdadera responsabilidad ética, que colma la dignidad de quien lo desempeña ${ }^{26}$; pero, también, supone una serie de obligaciones o límites a la voluntad del poderoso. Efectivamente, el ejercicio de la política es el escenario para la realización de la virtus ciudadana, quien la desempeña merece los mayores honores en la medida que ha de afrontar los desafíos más exigentes, con la única motivación del amor a la patria y la amistad ciudadana. Ahora bien, CiCERÓN, no sólo elogia la misión política a la que todo ciudadano de bien está llamado; también, delimita los contornos éticos de su ejercicio, mediante el establecimiento de la obligación de respetar los mores maiorum y cuidar la preservación de la res publica. En la peculiar conjugación de estas dos patrias (la familiar y la ciudadana), observa LLANO ALONSO, el talento político de CiCERÓN. Las costumbres de

${ }^{25}$ Ibidem, p. 63.

${ }^{26}$ Ibidem, p. 143. 
nuestros mayores conforman el bagaje cultural romano y la idea de Roma es entendida como una misión civilizadora, esto es, la expansión del modelo político de la cives $^{27}$. Se trataría de respetar y proteger la herencia cultural de los antepasados, al tiempo que se incrementa este patrimonio moral con la promoción de la libertad política y el iuris consensu romano. En consecuencia, hay dos límites insuperables para la política, cuya vulneración convertiría en tiránica cualquier clase de acción, estos son: la tradición cultural romana y su modelo político. La veneración a la tradición y el amor atento a la constitución política de la Roma republicana, que profesa CICERÓN, constituyen la base material de la virtus ciudadana

El tercer capítulo lo dedica, nuestro autor, al estudio de la continuidad histórica que ha tenido la teoría política republicana de CICERÓN. En el decurso de sus páginas, el lector descubrirá ideas, que otrora formuladas por el Arpinate, van sucediéndose a lo largo de la historia de las naciones como un reclamo insatisfecho de nuestra vivencia política. LlANO ALONSO comienza este recorrido en la Italia del Trecento y el Quattrocento, ocupándose inicialmente de su recepción vernácula por BRUNETTO LATINI (p. 80) y prestando especial atención a la influencia del cónsul romano en la filosofía de MARSILIO DE

${ }^{27}$ Ibidem, p. 67.
PADUA. FERNANDO LLANO reencuentra en el filósofo patavino las claves del pensamiento republicano de Cicerón: el imperio de la ley, la participación del pueblo en la configuración del poder $y$, por supuesto, el encomio al cuidado de la cosa pública y el celo en el ejercicio del $\operatorname{poder}^{28}$. La especial dignidad $\mathrm{u}$ orgullo que revela la acción política de CICERÓN, volverá a ser alabada por el genial humanista PETRARCA, quien, además, recuperará la doctrina romana del bonus vir para la formación retórica de la élite intelectual ${ }^{29}$. Esta virtud ciudadana, la protección de la patria y la alabanza a la imagen de Roma trazada por Cicerón, será una constante en los humanistas italianos del siglo XIV como LEON BAtTista Alberti, Vespasiano DA BisticCI, Poggio Bracciolini, LeONARdo BRUni,

GianNOZZO MinetTi, NicCOlÒ Niccoli, Coluccio Salutati, Matteo Palmieri, Marsilio Ficino y Pico Della MiRANDOlA ${ }^{30}$

El republicanismo mantendrá en el Cinquecento italiano una infatigable fortaleza, pues, a juicio del autor, la resistencia a la tiranía de los Medici y el recuerdo nostálgico de la grandeza republicana, servirán de nutriente para la definitiva instauración de la República de Florencia en el siglo XVI. Destaca el profesor LlANO las figuras de MAQUIAVELO y GUICCIARDINI, quienes en sus escritos realizan

\footnotetext{
${ }^{28}$ Ibidem, pp. 81-84

${ }^{29}$ Ibidem, p. 85.

${ }^{30}$ Ibidem, p. 86.
} 
una inigualable defensa del modelo republicano. GUICCIARDINI revitaliza la idea de constitución mixta de CICERÓN aplicada ahora a la realidad florentina $^{31}$ y MAQUIAVELO aún manteniendo una concepción muy diferente de la actividad política, demuestra un gran conocimiento de la obra de CiCERón. Más aún, Llano AlOnso observa la pervivencia de la idea de constitución mixta y la igualdad ciudadana como piezas claves para comprender su modelo de república ${ }^{32}$, textualmente afirma el profesor: "teniendo en cuenta los valores republicanos compartidos por Maquiavelo: bien común, virtud cívica, libertas, vivere politico, no creo desacertado vincular al pensador florentino con la tradición doctrinal del patriotismo republicano (al frente de la cual figura Cicerón)" $" 33$.

Al igual que en Florencia, el republicanismo ciceroniano también encontrará su lugar en la Inglaterra de la Guerra Civil y la Revolución Gloriosa, en el siglo XVII. A ello le dedica una parte importante de este tercer capítulo y brotan maduros los resultados de sus investigaciones en Oxford. Primero destaca FERNANDO Llano que la filosofía de HobBes debe entenderse como una reacción monárquica a los estudios humanistas que conformaban la educación de la juventud inglesa. En este sentido,

\footnotetext{
${ }^{31}$ Ibidem, p. 89.

32 Ibidem, p. 93.

33 Ibidem, p. 95.
}

HoBBES conocía bien la obra de CiCERÓN, como la de otros grandes clásicos de la cultura grecorromana, si bien eran vistos como una amenaza para la fortaleza del Estado, dada la defensa republicana de la democracia ${ }^{34}$.

Frente al absolutismo monárquico, cobraría fuerza el pensamiento republicano inspirado en CiCERÓn de MiLtOn, HARRINGTON y SIDNEY $^{35}$. Es MiLTON en quien observa FERNANDO LLANO más claramente la influencia del Arpinate, pues, estima la vulnerabilidad humana como causa de la vida en sociedad, defiende la libertad ciudadana frente a los excesos de la monarquía y el imperio de la $1 e y^{36}$. HARRINGTON define a CICERÓN como "honest man" y comparte con él los valores esenciales de la teoría republicana: la virtud cívica, la constitución mixta y el imperio de la 1 ley ${ }^{37}$. SIDNEY, el tercer whig, defiende el origen popular del poder y es, también, partidario del modelo de constitución mixta republicana y el escrupuloso respeto a la legalidad ${ }^{38}$

Llegados a este punto, no sorprende encontrar las huellas del pensamiento ciceroniano en el pensamiento de JOHN LOCKE, quien regresa a la idea del iuris consensu (ley común) como fundamento del estado civil y el respeto a las

\footnotetext{
${ }^{34}$ Ibidem, p 103.

${ }^{35}$ Ibidem, p. 105.

${ }^{36}$ Ibidem, pp. 106-107.

${ }^{37}$ Ibidem, pp. 108-109.

${ }^{38}$ Ibidem, p. 110.
} 
leyes como clave para la libertad política ${ }^{39}$. Vuelve a tomar la senda de las formas clásicas de gobierno para defender la monarquía parlamentaria inglesa $^{40}$. THOMAS PAINE, en cambio, anunciará sin dudas su preferencia por un sistema democrático representativo, donde la el imperio de la ley, el bien común y las virtudes cívicas sean las bases de la convivencia humana ${ }^{41}$.

El profesor LLANO culmina su tránsito por la historia inglesa, detallando la influencia del pensamiento clásico romano en el pensamiento de los Commonwealth's men del siglo XVIII como TRENCHARD y GORDON. Especialmente, este último a través de sus Cato's Letters se sirve de la historia de Roma para ilustrar a sus contemporáneos acerca de las virtudes del republicanismo liberal ${ }^{42}$. Tampoco olvida el autor la figura de MiddLETon y DodDRIDGe, quienes encontraron en CICERÓN el mejor ejemplo para la educación e instrucción de la élite inglesa ${ }^{43}$.

Finaliza este tercer capítulo con el análisis de la influencia del pensamiento clásico republicano (ARISTÓTELES, CICERÓN, MaQuiavelo, Guicciardini) en los Founding Fathers norteamericanos ${ }^{44}$. Nuestro autor, cree encontrar la influencia de Cicerón en las obras de
John Adams y Thomas Jefferson: el primero, por su conocida posición favorable a la división de poderes y al Rule of justice; el segundo, por su devoción intelectual hacia la figura de CICERÓN. En consecuencia, concluye LlANO ALONSO: "el republicanismo norteamericano, pese a sus diversas facetas y vertientes, siente una común admiración por la constitución de la Roma republicana, su modelo de virtus cívica y el concepto de libertas" ${ }^{\prime 5}$.

\section{IIII. La ética humanista y universal de} CICERÓN。

La tercera parte, que contiene el último capítulo, se reserva para el desarrollo del ideal ético cosmopolita del Arpinate, éste es un tema que el autor conoce con denotado rigor y profundidad; no en vano, ya fue objeto de una anterior monografía sobre el cosmopolitismo en KANT ${ }^{46}$. Sorprenderá al lector encontrar en CICERÓN una defensa de un humanismo universalista, que supera las convicciones estoicas sobre la humanitas, porque no se trata solamente de un concepto ético; más aún la humanitas es una realidad ético-jurídica que subyace en la particular experiencia política romana y su visión

\footnotetext{
${ }^{39}$ Ibidem, p. 111.

${ }^{40}$ Ibidem, p. 112.

${ }^{41}$ Ibidem, p. 113.

${ }^{42}$ Ibidem, p. 116

43 Ibidem, p. 117.

${ }^{44}$ Ibidem, pp. 117-120.
}

45 Ibidem, p. 120.

46 LLANO ALONSO, F. H., El humanismo cosmopolita de I. Kant, Madrid, Instituto Bartolomé de las Casas, 2002. 
del mundo ${ }^{47}$. Ello convierte a CICERÓN y a su idea de Roma en el primer artífice teórico de la idea de civitas maxima, base de la teoría cosmopolita.

CiCERÓN supera el etnocentrismo griego de modo que su idea de la humanitas se trata de una visión universal y plural del género humano, en la que el elemento de unión en la diversidad se logra mediante el vínculo jurídico político que crean las leyes ${ }^{48}$. Como afirma nuestro autor: "En realidad fue Cicerón el primero en imprimirle un giro político a la idea de diversidad de hombres reunidos en torno al concepto de género humano (genus humanus) que convive en una patria común y universal (patria communis, civitas universa)" $"$. El eximio romano, de acuerdo con esta fe humanista, concibe el derecho de gentes como un derecho universal, que hunde sus raíces en el mismo derecho natural. En el ius naturale se funda la fraternidad del género humano y, así, el primado de la razón se revela como condición de la igual dignidad humana ${ }^{50}$

En esta comunidad del género humano se funda el imperativo (ético) racional de conceder la residencia y permitir la entrada, convivencia y comercio de los extranjeros; anticipa con siglos de antelación la doctrina del ius communicationis

${ }^{47}$ LLANO ALONSO, F. H., El gobierno de la razón, op. cit., p. 152.

48 Ibidem, p. 129.

${ }^{49}$ Ibidem, p. 132.

${ }^{50}$ Ibidem, pp. 139-141. de VITORIA ${ }^{51}$. Más aún, esta defensa de la unidad fraterna realizada por CICERÓN, piensa LLANO AlOnso, anticipa la filosofía de KANT, porque esta misión ética sólo es alcanzable mediante la extensión de la romanitas y la acción de un derecho común (romano) a todos los pueblos. Por esta razón, el profesor de Sevilla considera más acertado examinar el planteamiento ciceroniano de acuerdo con la perspectiva iusracionalista que le define $y$, en consecuencia, más que cosmopolitismo, deberíamos concluir su universalismo jurídico-político ${ }^{52}$.

Nuevamente, LLANO AlONSO ha explicado históricamente la filosofía humanista de CiCERÓN, no sólo mediante las fuentes primarias del autor, sino, también, por su proyección histórica en filósofos de enorme envergadura para la civilización occidental, como lo son VITORIA y KANT. La filosofía universalista de CiCERÓN, dada su continuidad histórica, se ofrece ahora como una prueba de la philosophia perennis de $\mathrm{STEUCO}^{53}$. En gran medida, creo que el profesor LLANO alumbra esta clase de conocimiento, porque sirviéndose de la figura angular de CiCERÓN nos señala las pistas de un humanismo eterno, a través de ZENÓN DE CiTO, PANECiO , Lactancio, Pico Della Mirandola, Vitoria,

${ }^{51}$ LLANO ALONSO, F. H., "Cicero and Natural Law", op. cit., p. 166.

52 LLANO ALONSO, F. H., El gobierno de la razón, op. cit., p. 153.

${ }^{53}$ SCHMITT. C. B., "Perennial philosophy: from Agostino Steuco to Leibniz", Journal of the History of the Ideas, vol. 27, n. 4, (1966), pp. 517. 
PUfFENDORF, KANT, RAWLS, HABERMAS y NUSSBAUM

Utilizando las mismas palabras del autor: “Cicerón no amplía solamente, con su visión iusnaturalista y omnicomprensiva de la realidad jurídica, la estricta visión formalista del Derecho de la jurisprudencia romana tardorrepublicana, sino que también eleva hasta su más altas cotas la idea de racionalidad humana alumbrada por la doctrina estoica de la oikeiosis" $"$.

\section{Epílogo.}

Concluye Llano Alonso en su Epílogo con una vigorosa llamada a la oportunidad de recuperar el pensamiento de CICERÓN, como ejemplo de compromiso ético, jurídico y político. Acaso dimensiones íntimamente conectadas en el modo de enfrentar la existencia de nuestro aclamado filósofo latino. Lo explica el autor, CICERÓN combina las convicciones éticas con la responsabilidad política. Es una armonización de intereses y convicciones, resultado de una vocación a la excelencia humana, que sólo en él alcanzó tan elevadas exigencias. ¡Ojalá contásemos entre nosotros con un excelso magistrado a su imagen! Quizás, entonces, florecería esta vocación de servicio a la república,

${ }^{54}$ LLANO ALONSO, F. H., El gobierno de la razón, op. cit., p. 158. a la cual FERNANDO LLANO apela nostálgico. No se ve, no, este republicanismo comprometido con el derecho y la democracia, será que este horizonte está oscurecido por la bárbara corrupción, $\mathrm{o}$, de tanta contaminación semántica e ideológica. Si uno quiere volver a reencontrarse con la pureza prístina de la virtus ciudadana, deberá alzar la vista a las cumbres filosóficas, donde habitan los clásicos. Debe aplaudirse el libro del doctor LlANO ALONSO, porque nos reconcilia con el genio romano y vuelve a dar voz a su mensaje ético y humanista, silenciado por el olvido.

Uno de los grandes méritos de este estudio, a mi juicio, consiste en la precisión del análisis realizado por el autor, lo que se comprobará fácilmente al observar la bibliografía empleada, tanto la referida a fuentes directas como indirectas. Con algo más de sutilidad, se descubre la elección cuidadosa de las ediciones que comprenden la obra de CICERÓN, pues, LLANO ALONSO parece haberse pertrechado con las mejores. Claro que este saber investigar, lo que nos revela es la pasión documentalista del profesor sevillano.

Otras de estas pasiones productivas del autor es su vocación histórica y netamente se manifiesta a lo largo de la obra, el profesor LLANO desarrolla con rigor la historicidad de la filosofía de CICERÓN, desde sus influencias 
estoicas hasta sus proyecciones iusracionalistas, de la república romana a los founding fathers; y, gracias a ello, nos demuestra hasta qué punto la historia es el cauce a través del cual se exterioriza la racionalidad del acontecer humano.

No obstante, en la continuidad histórica de las ideas republicanas de CICERÓN un paréntesis queda abierto para el caso de Hispania. Sumándome al propósito del autor, en el siglo XV castellano, también, resuenan los ecos de la filosofía humanista y republicana de Cicerón en la Primera Escuela de Salamanca. En ella, destaca FERNANDO DE ROA como insigne ejemplo de la defensa del imperio de la ley, la constitución mixta y el poder como officium ético. No es coincidencia que este catedrático burgalense predecesor de VITORIA en la Catedra Prima desarrolle su visión mesocrática y republicana de la política, bajo el influjo de las traducciones de las obras aristotélicas de LEONARDO BRUNI y que gran parte de sus postulados teóricos encuentren reflejo en el Tractado de Republica de ALONSO DE CASTRILlo. Nuestra historia nos regala las figuras de MADRIGAL (el Tostado), OSMA, ROA y CASTRILlo formando un cuerpo de doctrina política representativo de la Castilla renacentista. 